\title{
Design of Electric Racing Vehicles: An experience of interdisciplinary project-based education in engineering
}

\author{
José Fernández Ramos ${ }^{1}$, Juan Jesús Fernández Lozano ${ }^{2}$, Alfonso Gago Calderón ${ }^{3}$ \\ ${ }^{1}$ (corresponding author) University of Malaga,Dpt. Electronics, 2.2.41, josefer@ctima.uma.es \\ ${ }^{2}$ University of Malaga, Dpt. Systems Engineering and Automation,jifl@uma.es \\ ${ }^{3}$ Fundación Solitec, Dept. I+D, CI Marea Baja N 1929006 Málaga, alfonso_gago@solydi.com
}

\begin{abstract}
This paper describes a project based learning program carried out in the E.T.S.I.I. of the University of Malaga, Spain, whose main objective is the organization of a team for the development of experimental electric racing vehicles and their evaluation in competitive races. It is shown the work done during the first two years of the project, highlighting the most important aspects of the experience: the training focused on senior students (capstone courses), the training focused on freshmen (cornerstone courses) and the university-industry collaboration for the manufacture of the prototypes and equipment designed.
\end{abstract}

Keywords: Project-based Education, Electric Racing Vehicles, Active interdisciplinary learning, University-Industry collaboration

\section{Introduction}

Nowadays, electric vehicles (EVs) represent an advantageous alternative to the internal combustion vehicles (ICVs) in some applications such as urban mobility due to the availability of practical and marketable EV models.

However, most people do not know or understand all the specific characteristics that make of the EVs an advantageous option. And even a more serious problem is that this lack of this knowledge is also found in engineering students and professionals. All these together makes that the development of this technology is being slower than it could be and is a serious drawback for its wide spread.

Solar and electric car races for students started in the mid-80s of last century as an attempt to overcome some of these problems: First of all, they show people the benefits and possibilities of the EVs in an attractive format. Moreover, they allow engineering students to become familiar

This work has been partially done under the project International Campus of Excellence Andalucía TECH in the framework of the Programme International Campus of Excellence of the Educational Ministry of Spain with this technology and to face the challenges of designing vehicles under stringent constraints. In contrast to many ICV races, the goal of most of the EV races is not to be the fastest but to minimize the energy consumption of the vehicles, that is, the winner is the most energy efficient vehicle.

Nowadays, such races take place on the five continents and so involve worldwide universities, research centers and enterprises [1-5]. For the engineering schools, there are a big number of topics which have technological development and/or research aspects which can make the design and manufacturing of an Electric Race Vehicle (ERV) to be of great interest for professors and students [6]. In detail, all the issues involved in the design of an ERV can be used as the basis for project-based learning experiences that reinforces the knowledge and motivation of the students. Finally, the development of this type of project encourages the collaboration of the engineering schools with the industry. This is another challenge faced by universities in the new learning environment of the European Higher Education Area (EHEA) that is currently being implemented in Spain. 


\section{Project development}

In this context, the organization of a team of students was started by a group of professors from the Escuela Técnica Superior de Ingeniería Industrial (ETSII) of the University of Malaga (UMA) in the early 2011 as an opportunity to start an educational project based. Its main objectives would be the design and development of ERVs and their participation in specific races for this type of vehicles. From the beginning, it was looked for and raised the collaboration with small business located in an area close to the University of Malaga to help in the manufacturing process of the prototypes and to allow the students to have the experience of working in a real production environment.

The initial project was based on two working lines: the design and prototype manufacturing of ERVs and the participation in a few of the competitions held annually in Europe. Both lines are closely connected. First, the design of the vehicle is carried out according to the regulations of these competitions, which limit many of its features such as physical dimensions, engine power, battery type, etc. and they also have very strict specifications and regulations regarding safety such as the characteristics of the braking system, safety switches, etc. [7]. On the other hand, the involvement in races is an ideal benchmark to evaluate the performance of the vehicles that are being generated and to validate the technological solutions undertaken. The experience gained in these races is used to identify problems and needs and to seek solutions for them, which will be tested and analysed again in future races.

The ERVs design project was initially approached as a Project Based Learning (PBL) methodology in an educational environment known as "capstone course", that is a design course typically taken in the senior year, in which students put into practice the skills acquired throughout his career, usually doing a practical work and presenting and defending it before an academic board. [8]. In the ETSII, this type of work is called Graduation Project and is mandatory for all students.

Three students in their final year of Degree were selected to create the team and a partner company Trota Quad Ltd.- offered two prototypes of plug-in ERVs that were built using standard components of electric bikes.

The first work of the students was making all the necessary modifications to adapt these vehicles to the rules of the Solar Race of the Region of Murcia (SRRM), Cartagena (Spain), which is the closest racing event of this nature to the city of Malaga. They also performed all the technical documentation of the vehicles, including drawings of the frame and bodywork, wiring diagrams, component descriptions, etc. Finally, all the improvements that could be introduced in vehicles were analysed. Based on this study, one of the decisions was to develop an electronic system to accurately measure the state of charge of the batteries. This work was commissioned to one of those students as its Graduation Project.

The participation in the SRRM was planned as a

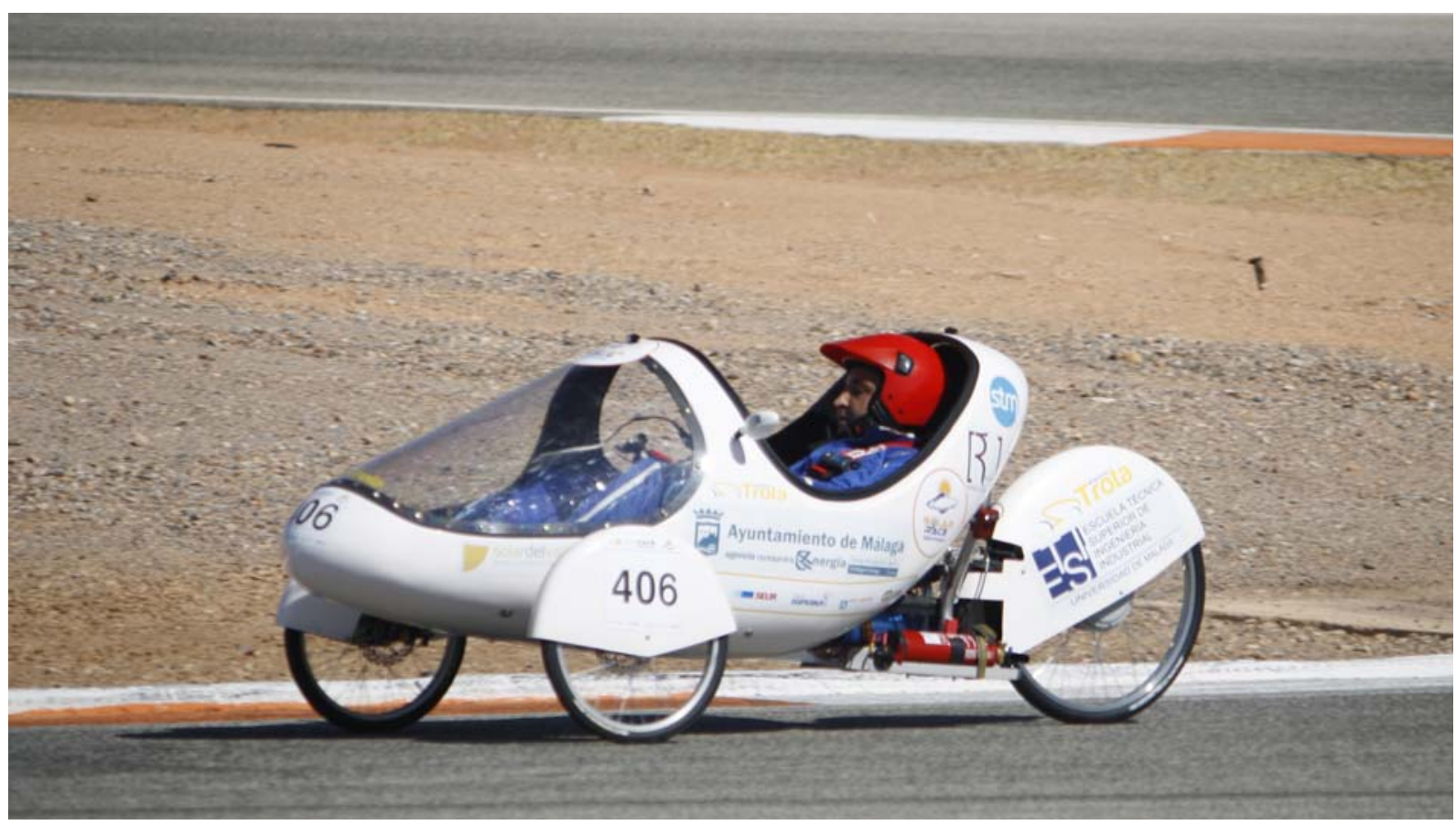

Figure 1: TE01 in SRRM 2011 


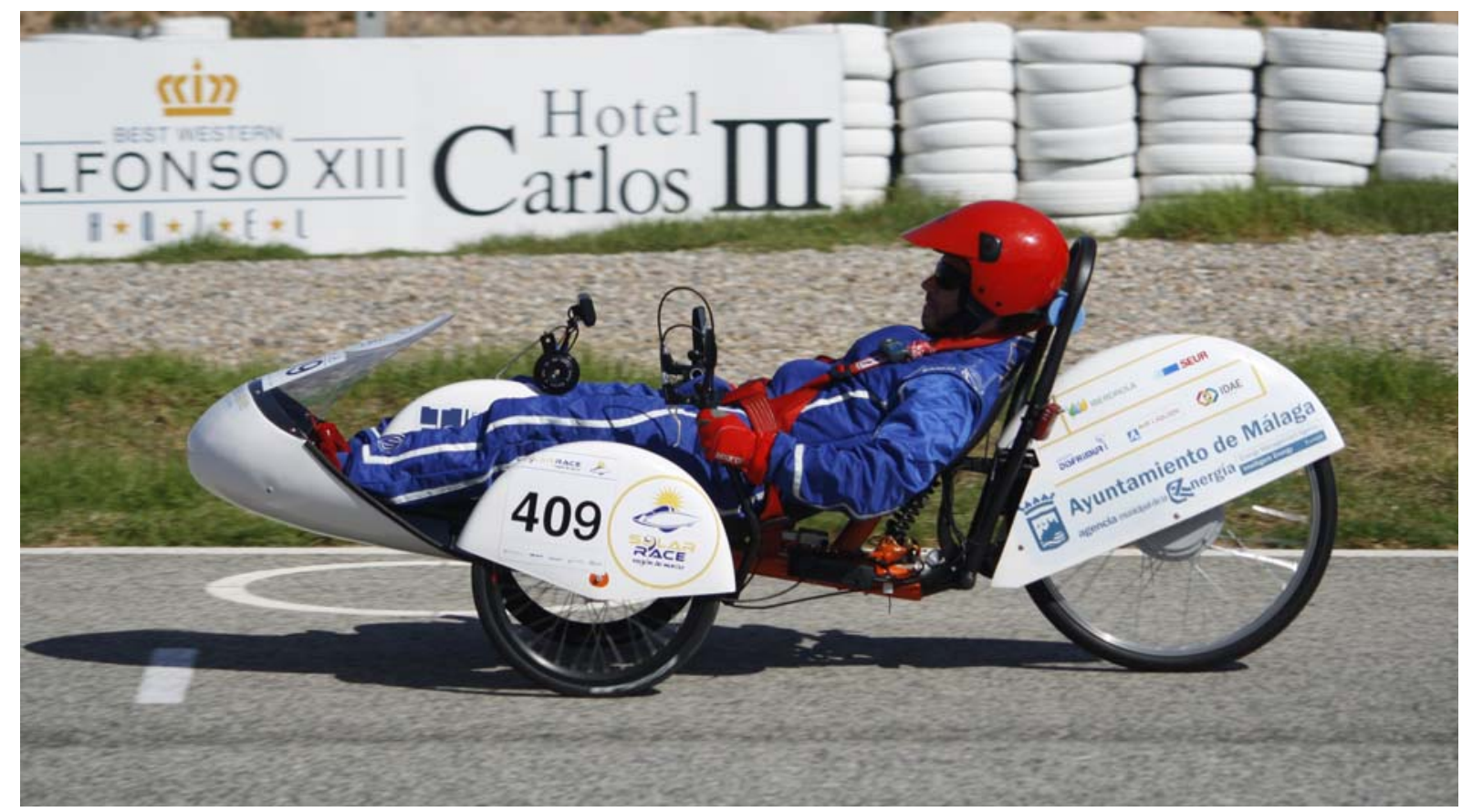

Figure 2: TE02 in SRRM 2011

main goal for 2011. To raise the funds necessary to participate in this race, it was sought the help of the municipal government and its energy agency (AGEMA) and of the E.T.S.I.I. where the team belong to.

Finally, after a great effort, the two vehicles, called TE01 and TE02 (Figs. 1 and 2), were ready to participate in the category of 'electrical plug-in of experimental vehicles' in that race during 13, 14 and 15 October 2011.

The most important results obtained from this participation were:

- The two cars showed an optimum performance, they completed all rounds of the race without any technical problem and showed an appropriate robustness in both mechanical and electrical components.

- The power consumption of the vehicles was high, a fact that was attributed to the high weight of the drivers, nearly $20 \mathrm{~kg}$ higher than any driver of other teams. This was the main reason why it was not achieved a good rankings at the end of the race.

- It was detected the need of a telemetry system in order to know -in real-time basisthe operating parameters of the vehicle to optimize its performance.

The main conclusion after the first year of the team was the confirmation of the great opportunities offered by the ERV design to generate a much more ambitious educational project, involving not only the students that are finishing their degrees, but also those on the first year of the engineering curriculum. This type of educational methodology, known as "cornerstone engineering courses" [8-9] is increasing in popularity because it allows students to have an overview of engineering from the beginning, perceiving it as an integration of different specialties and not only as a set of independent disciplines. In addition, these courses are also seen as a means to enhance students' motivation and their retention in engineering, in part because they introduce engineering content and experience early in the curriculum, in part because they also put first-year students into direct contact with engineering faculty [8].

These arguments were used to organize the new race team for 2012. It was searched two types of students: First, students in the final year of their degree were selected, which took care of specific tasks and projects to improve the vehicles, in particular, the development of two different telemetry systems: one based on unlicensed band radio frequency (RF) and other based on mobile phone operator. On the other hand, freshmen of all ETSII specialties (mechanical, energy, electrical, and mechatronics) were selected to perform a training plan, to be developed in two years, that includes the following stages:

1. Basic training: It is based on an approach "from practice to theory": working sessions 


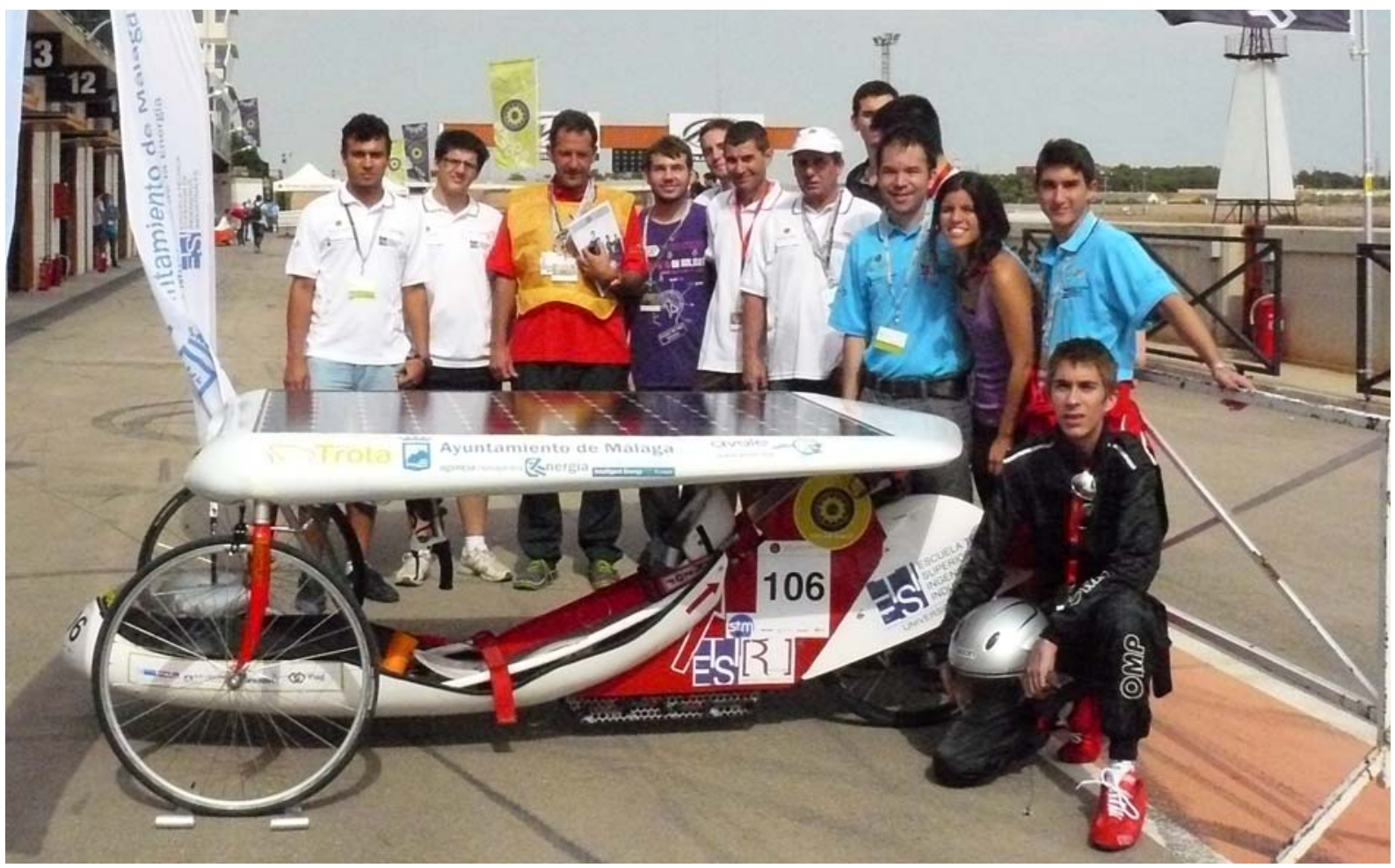

Figure 3: Racing Team in SRRM 2012

were planned in the fields of electricity, energy, aerodynamics, mechanics, electronics and control.

2. Improving prototypes: Analysis of the existing ERVs components and replacing some of them to improve the overall performance of the vehicles.

3. Designing and manufacturing a completely new ERV that is suitable to race on the 'street vehicle' category of any electric vehicle competition.

In parallel with the organization of the new team's staff, it was planned the development of a new prototype of an ERV included in the category of 'solar photovoltaic' that was started in the early 2012 in partnership with the firm Trota Quad Ltd. The aim of this new vehicle was to participate in the SRRM-2012. The first tests were made in July 2012 and the new vehicle, called TS01, competed in the race obtaining a creditable third place in its category.

To summarize, the activities carried out by the team during the year 2012 were as follow:

- There have been two Graduation Projects finished by senior students, entitled "Control system for recharging batteries of electric vehicles" and "Telemetry system for electric vehicles based on GPRS and ultra-low power microcontroller."

- The five basic training sessions with freshmen have been completed. They have studied the structure and operation of all the basic components of the team's ERVs: electric motor, battery, solar panel, power controller, on board computer, frame, shell, steering, etc.

- A new prototype of a solar photovoltaic ERV has been developed.

- The team (Fig. 3) had participated in the SRRM during the 4th, 5th and 6th of October 2012 with two vehicles: the TE02 (plug-in ERV) and the TS01 (solar photovoltaic ERV) (Fig. 4). This participation was supported and sponsored by small businesses such as Trota Quad S.L. and Solydi and institutions such as AVELE, AGEMA and the ETSII (UMA).

\section{Discussion}

Although the project is still ongoing and it is too early to provide definitive results, it is possible to anticipate the following lessons learned from it:

- It is essential to have the support of the school of engineering, both in the tasks of selecting and managing students and using their facilities and equipment. 


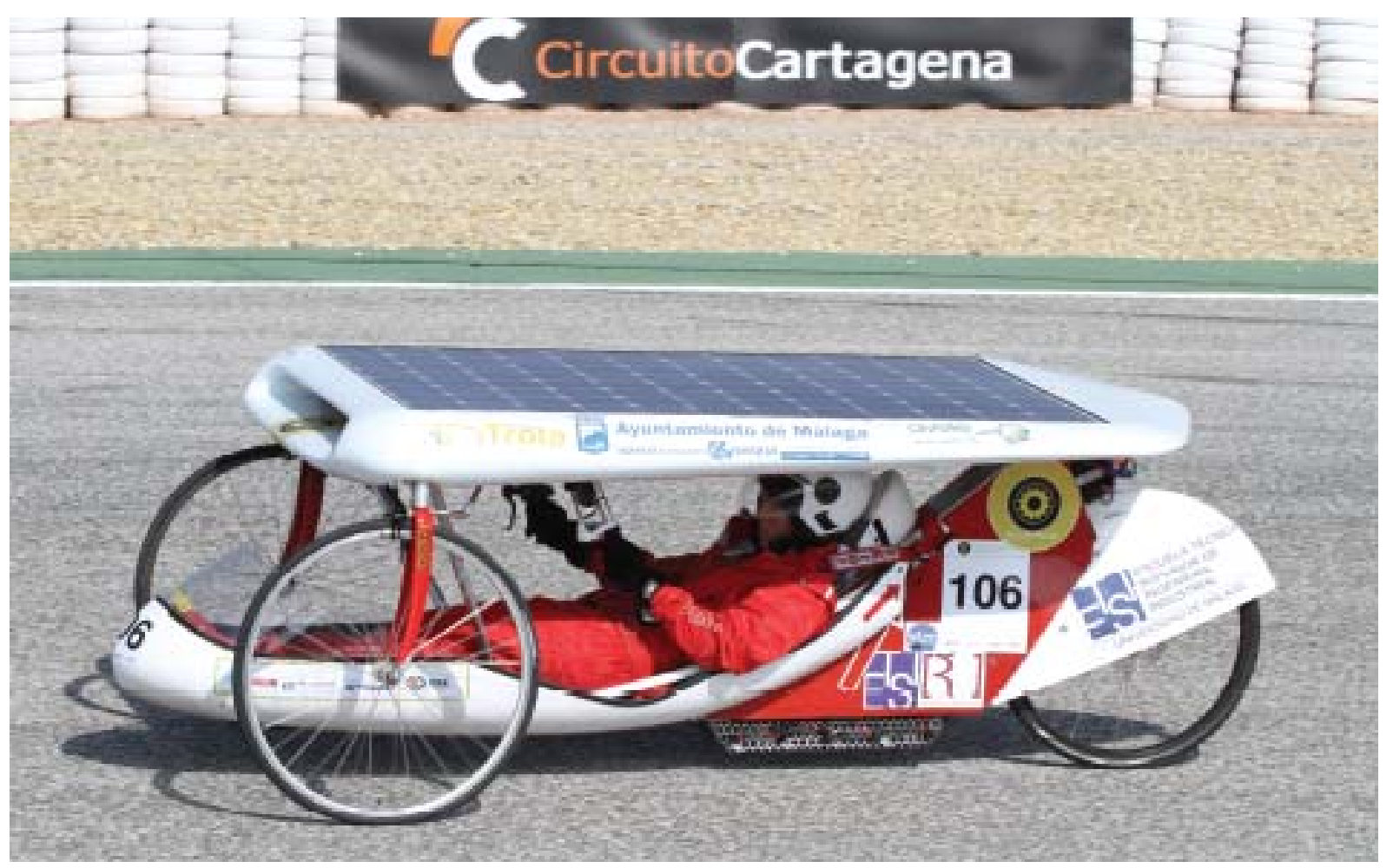

Figure 4: TS01 in SRRM 2012

- It is essential to find companies that collaborate actively in the project.

- The main problem is finding funds to afford the costs of development and participation in the races. It is necessary to form a "Fund Raising Team" to address this role.

\section{Conclusions}

The project of 'Design of Electric Racing Vehicles' is a good example of PBL in the field of engineering because:

- It integrates a set of core subjects in engineering: mechanical, energy, electrical, electronics, control, and aerodynamics.

- It is well suited to be applied on the methodology of "cornerstone courses".

- It represents a framework for universityindustry collaboration.

\section{Acknowledgments}

We wish to express our sincere gratitude to all the students who built up the team and, especially, to Ignacio Castillo and Leo Mérida, from Trota Quad Ltd., without their hard work and dedication this project would have never been possible.

\section{References}

[1] B. Rogow, Suntrakker - A student-designed solar vehicle, Electrical Insulation Conference, 1997, and Electrical Manufacturing \& Coil Winding Conference. Proceedings, 22-25 Sep 1997, 694-697, doi: 10.1109/EEIC.1997.651281

[2] R. Mangu et. Al., Design, Development and Optimization of Highly Efficient Solar Cars: Gato del Sol I-IV, Green Technologies Conference, 2010 IEEE, 15-16 April 2010, 16,. doi: 10.1109/GREEN.2010.5453800

[3] K. Sternal et. Al., Electric Vehicle for the Students' Shell Eco-Marathon Competition. Design of the Car and Telemetry System, 12th International Conference on Transport Systems Telematics (TST 2012), October 2012, 26-33.

[4] N. Alnunu et. Al., Design of Qatar University's first solar car for Shell Ecomarathon competition, Renewable Energies and Vehicular Technology (REVET), 2012 First International Conference on, March 2012, 49-54, doi: 10.1109/REVET.2012.6195247

[5] Suita, Y. et. Al., Driving Performances of Solar Energy Powered Vehicle with Novel Maximum Power Tracking Control for a 
Solar Car Rally, Industrial Technology, 2006. ICIT 2006. IEEE International Conference on, 15-17 December 2006, 1218-1223,. doi: 10.1109/ICIT.2006.372463

[6] W.B. Berry et. Al., A race car, the formula lightning as an engineering education platform for enhancing the engineering development of the electric car between industry and university, Power Electronics in Transportation, 1994. Proceedings, 20-21 October 1994, 41-46,. doi: 10.1109/PET.1994.572354

[7] Official Rules of SOLAR RACE 2012

http://www.murciasolarrace.com/sites/defaul t/files/adjuntos/Official\%20Rules\%20SRR M2012.pdf

accesed on 2013-13-2

[8] C. Dym et Al., Engineering design thinking, teaching, and learning, Journal of Engineering Education, ISSN: 10694730, 94 (2005), 103-120.

[9] B.I. Hyman, From Capstone to Cornerstone: A New Paradigm for Design Education, International Journal of Engineering Education, ISSN: 0949149X, 17(201), 416-420 


\section{Authors}

José Fernández Ramos received the M.S. degree in Physics from the University of Seville, Spain, in 1984, and the Ph.D. degree from the University of Malaga, Spain, in 1998.

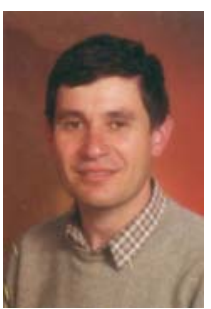

From 1984 to 1990, he worked in the R\&D department of INFESA, Spain. In January of 1991, he joined the University of Málaga as Associate Professor in Electronic Engineering.

His current research interests include LED technology, Electric Vehicles and Photovoltaic Systems.

Jesús Fernández Lozano received the $\mathrm{ME}$ degree in Industrial Engineering (Electrical and Electronic major) from the Universidad de Málaga in 1997 and a Dr.-Eng. degree in Robotics from the same University in 2002. He is currently an Associate Professor in the Department of Automation and Systems Engineering. His main research interests are robotics and mechatronics applications, from surgical robotics to intelligent vehicles. He is author of several journal and conference papers, and he has filed 10 patents, one of them international. He is Director of the School of Industrial Engineering of the Universidad de Málaga.

Alfonso Gago Calderón received the M.S. (best academic achievement), and Ph.D. degrees in Industrial Engineering in 2002 and 2010, respectively, and the M.S. degree in audiovisual systems in 2010, all from the University of Málaga, Spain.

From 2003 he is the director of the R\&D department of SOLITEC, Spain. His current research interests include LED Lighting, Large Audiovisual Systems and Electric Vehicles. 